ler et al. suggest that it is the secretion rather than the synthesis of these proinflammatory mediators that may account for the differences in the reaction of rats versus humans to superagonistic antiCD28 antibodies and may account for why the cytokine storm observed in humans receiving TGN1412 could not have been predicted based on preclinical work in rodents receiving JJ316.

The first wave of $\mathrm{T}$ cell activation disappeared within 48 hours and was followed by a second wave of expansion of $\mathrm{CD}^{+} \mathrm{CD}_{25}{ }^{+} \mathrm{FoxP}^{+}$Tregs (5), involving Treg enlargement, polarization, and increased motility. The authors suggest that the cytokine storm observed in TGN1412-treated individuals was likely a consequence of the first wave of $\mathrm{T}$ cell activation and that the beneficial effects of superagonistic anti-CD28 antibody therapy previously observed in rodent models of autoimmune disease were likely the result of this second wave of activation that selectively affects Tregs. In summary, Müller et al. further illuminate our understanding of the mechanisms of action of the superagonist anti-CD28 antibody, and the data reinforce that this therapeutic approach will require much further investigation before it can be applied to humans.

\section{Inspiring trust in drug development}

Human volunteers who chose to participate in clinical trials trust in our ability to protect them as much as possible from the dangers of investigational agents. Trust is not an intangible quality but rather something real and concrete. Trust is not only about integrity but also about competence. People expect investigators, sponsors, contract research organizations, and regulatory authorities to have the talents, skills, knowledge, and capacity to carry out their responsibilities. We may lose their trust if we fail to meet our commitments to afford optimal protection of human subjects in trials. Participation in clinical trials will always have inherent risks, but hopefully lessons will be learned from the TGN1412 experience that will benefit research subjects in the future.

Address correspondence to: E. William St. Clair, Department of Medicine, Box 3874, Duke University Medical Center, Durham, North Carolina 27710, USA. Phone: (919) 684-4499; Fax: (919) 684-8358; E-mail: stcla003@mc.duke.edu.

1. Suntharalingam, G., et al. 2006. Cytokine storm in a phase I trial of the anti-CD28 monoclonal antibody TGN1412. N. Engl. J. Med. 355:1018-1028.

2. Beyersdorf, N., et al. 2005. Selective targeting of regulatory $\mathrm{T}$ cells with $\mathrm{CD} 28$ superagonists allows effective therapy of experimental allergic encephalomyelitis. J. Exp. Med. 202:445-455.

3. Schmidt, J., et al. 2003. Treatment and prevention of experimental autoimmune neuritis with superagonistic CD28-specific monoclonal antibodies. J. Neuroimmunol. 140:143-152.

4. Rodríguez-Palmero, M., et al. 2006. Effective treatment of adjuvant arthritis with a stimulatory CD28-specific monoclonal antibody. J. Rheumatol. 33:110-118.

5. Müller, N., et al. 2008. A CD28 superagonistic antibody elicits 2 functionally distinct waves of T cell activation in rats. J. Clin. Invest. 118:1405-1416.

6. Hünig, T. 2007. Manipulation of regulatory T-cell number and function with CD28-specific monoclonal antibodies. Adv. Immunol. 95:111-148.

7. TeGenero AG Investigator's Brochure. TGN1412 humanized agonistic anti-CD28 monoclonal antibody. Edition 1.1. http://www.circare.org/foia5/ $\operatorname{tgn} 1412$ investigatorbrochure.pdf.

8. Kenter, M.J.H., and Cohen, A.F. 2006. Establishing risk of human experimentation with drugs: lessons from TGN1412. Lancet. 368:1387-1391.

9. Dowsing, T., and Kendall, M.J. 2007. The Northwick Park tragedy - protecting healthy volunteers in future first-in-man trials. J. Clin. Pharm. Ther. 32:203-207.

10. Legrand, N., et al. 2006. Transient accumulation of human mature thymocytes and regulatory $\mathrm{T}$ cells with CD28 superagonist in "human immune system" Rag2 $2^{-/-\gamma_{c}-/-}$ mice. Blood. 108:238-245.

11. Stebbings, R., et al. 2007. "Cytokine storm" in the phase I trial of monoclonal antibody TGN1412: better understanding the causes to improve the preclinical testing of immunotherapeutics. J. Immunol. 179:3325-3331.

12. Nguyen, D.H., et al. 2006. Loss of siglec expression on T lymphocytes during human evolution. Proc. Natl. Acad. Sci. U. S. A. 103:7765-7770.

\title{
Tetraspanin in oncogenic epithelial-mesenchymal transition
}

\author{
Ruth J. Muschel and Annamaria Gal
}

Radiation Oncology and Biology, The Radiobiology Research Institute, University of Oxford, Oxford, United Kingdom.

\begin{abstract}
Members of the L6 family of membrane proteins, a branch of the tetraspanin superfamily, are overexpressed in tumor cells from many types of cancers. However, direct evidence of their oncogenic activity has not been previously shown. In this issue of the JCI, Lee et al. demonstrate that overexpression of the tetraspanin superfamily member TM4SF5 in human hepatocellular carcinoma cells causes cellular phenotypic changes that resemble classical descriptions of epithelial-mesenchymal transition (EMT), with some unique aspects (see the related article beginning on page 1354). They also show that these TM4SF5-mediated effects trigger tumor formation when these cells are injected into mice. The study implicates TM4SF5, for the first time to our knowledge, in EMT oncogenic pathways of cancer progression.
\end{abstract}

Nonstandard abbreviations used: EMT, epithelialmesenchymal transition; TM4SF5, transmembrane 4 L6 family member 5; ZO-1, zonula occludens-1.

Conflict of interest: The authors have declared that no conflict of interest exists.

Citation for this article: J. Clin. Invest. 118:1347-1350 (2008). doi:10.1172/JCI35308.
Over many years, cancer researchers have attempted to unlock the secrets of cancer cells by comparing the gene expression of tumor cells to that of their normal cellular counterparts. The genes so identified have in many cases proven to be important mediators of the transformed phenotype and have led in a few cases to the development of clinically useful therapeutics, such as antibodies directed against EGFR (implicated in many types of epithelial cancers) or human EGFR 2 (HER2/neu; often overexpressed in breast cancer). In 1997, Gress et al. performed a large-scale screen for differentially expressed genes in tissue from individuals with pancreatic cancer compared with tissue from individuals with chronic pancreatitis and identified transmembrane 4 L6 family member 5 (TM4SF5) as a gene upregulated in pancreatic tumors (1). TM4SF5 was noted to be homologous to the integral membrane protein $\mathrm{L} 6$ that is also overexpressed in a variety of malignant tissues (2). 


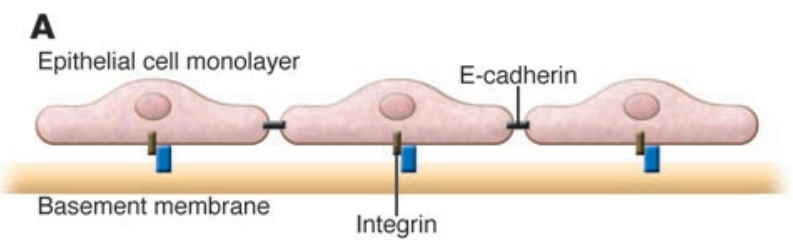

Polygonal morphology Cell-cell contact Contact inhibition

\section{B}

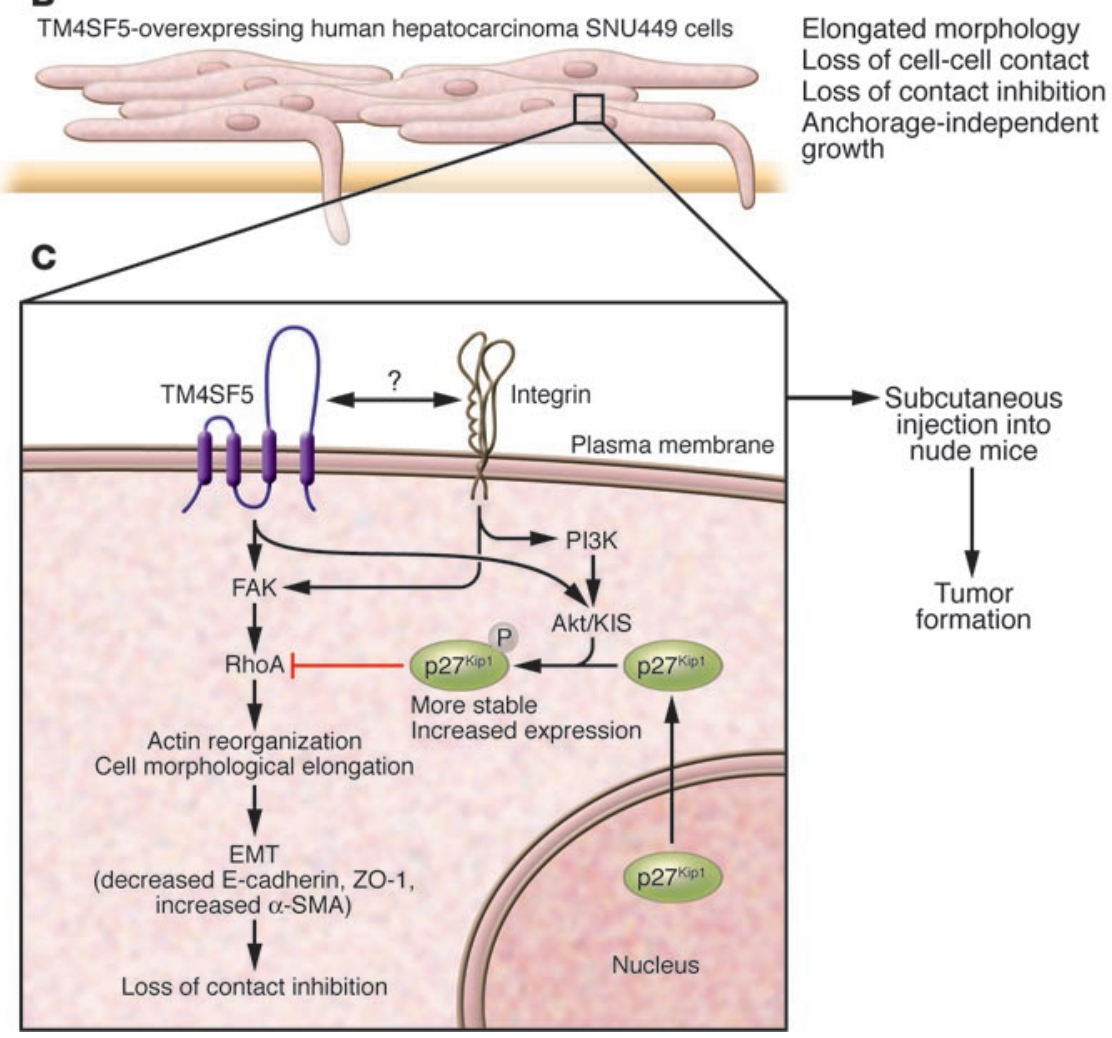

\section{Figure 1}

Tetraspanin superfamily member TM4SF5 induces EMT and tumorigenesis. (A) A monolayer of epithelial cells with polygonal morphology is held in formation by cell-cell contact between neighboring cells via molecules such as E-cadherin, as well as by the interaction of cell-surface integrins with proteins in the basement membrane. (B) In this issue of the $\mathrm{JCl}$, Lee et al. (15) show that overexpression of TM4SF5 in human hepatocarcinoma SNU449 cells results in phenotypic changes in these cells that resemble EMT, such as an elongated morphology, loss of cell-cell contact, and loss of contact inhibition, resulting in overgrowth. (C) Lee et al. (15) provide data indicating that TM4SF5 overexpression enhances the expression and cytosolic stability of p27 ${ }^{\text {Kip1 }}$, likely via kinase interacting with stathmin- (KIS-) and/or Akt-mediated phosphorylation. This results in RhoA inhibition and subsequent changes in cell morphology resembling EMT. The authors observed decreased expression of ZO-1 and E-cadherin (the latter occurring in a Snail1independent manner) and increased $\alpha$-SMA expression. Loss of cell-cell contact leads to loss of contact inhibition between cells and uncontrolled multilayer growth. Importantly, this uncontrolled growth could be blocked by suppression of TM4SF5 or p27 Kip1, Rho activation, or E-cadherin reexpression in these cells. Upon subcutaneous injection of TM4SF5-overexpressing SNU449 cells into nude mice, Lee et al. observed tumor formation. Figure modified from ref. 15.

\section{The tetraspanin superfamily}

TM4SF5 and L6 form a four-member homology group of membrane proteins that are structurally similar to tetraspanins. All members of the L6 family have four transmembrane domains. The $\mathrm{N}$ and $\mathrm{C}$ termini are cytoplasmic, as is one of the regions between the second and third transmembrane domains. This structure creates two extracellular loops between the transmembrane domains and is superficially similar to other tetraspanins that also have four transmembrane domains. However, the main extracellular domain of L6 and the tetraspanins are highly divergent, and the L6 family lacks a characteristic pattern of cysteines found in the tetraspanins. A DNA sequence-based phylogenetic tree places the L6 family on a branch that is related to but distinct from that of the tetraspanins (3). Hence the four L6 proteins are sometimes referred to as members of a tetraspanin superfamily.

While there is much biochemical and cell biological information about the tetraspanins, there is little information available about the L6 family. We do know that both L6 and TM4SF5 have been found to be overexpressed in some cancers, including gastric, prostate, breast, and pancreatic cancer, and that L6 has been associated with tumor cell invasion and motility in lung cancer $(4,5)$. Members of the tetraspanin family have also been shown to be tightly associated with integrins, which modulate cell shape, cell migration, and signal transduction in many cell types.

\section{The mechanism of epithelial cell plasticity}

The internal and external surfaces of the body, lining of blood vessels, and other small cavities are covered with a layer of epithelial cells that are held in formation via adhesive complexes between adjacent cells. These cells use the binding of cellsurface receptors, known as integrins, to extracellular matrix proteins to attach to the basement membrane (Figure 1A). When epithelial cells undergo transformation and become cancerous, they use these integrins to direct tumor cell invasion and cancer spread. Integrin engagement with extracellular ligands results in complex multiprotein structures that link the ECM to stress fibers that form the cytoplasmic actin cytoskeleton. The flow of signals from the ECM to the actin cytoskeleton is under the control of protein tyrosine kinases such as focal adhesion kinase (FAK) and members of the Rho family of GTPases and impacts the dynamics between cell adhesion and movement.

During normal embryonic development, a process known as epithelial-mesenchymal transition (EMT) involves the disaggregation of epithelial cells and the reshaping of these cells for movement (6). An analogous process is proposed to play an important role in the migration and metastasis of epithelial cancers (7-10). A better understanding of the factors that control epithelial cell organization may lend insight into how noninvasive, cancerous epithelial 


\section{Table 1}

Overview of different EMT modelsA

\begin{tabular}{|c|c|c|c|c|c|}
\hline Epithelial cell type & EMT inducers & Signaling pathways & Epithelial markers & $\begin{array}{l}\text { Mesenchymal } \\
\text { markers }\end{array}$ & $\begin{array}{c}\text { Actin } \\
\text { cytoskeleton }\end{array}$ \\
\hline $\begin{array}{l}\text { EpH4 (normal mouse } \\
\text { mammary gland } \\
\text { cell line) }\end{array}$ & $\begin{array}{l}\text { Cooperation of } \\
\text { Ha-RAS and TGF- } \beta \text {; } \\
\text { c-Jun; c-Fos }\end{array}$ & $\begin{array}{l}\text { Autocrine TFG- } \beta \text { and } \\
\text { ERK/MAPK, PI3K; } \\
\beta \text {-catenin/LEF }\end{array}$ & $\begin{array}{l}\text { E-cadherin, Z0-1 } \\
\text { downregulation }\end{array}$ & $\begin{array}{c}\mathrm{N} \text {-cadherin, } \\
\text { vimentin upregulation }\end{array}$ & $\begin{array}{l}\text { Actin stress } \\
\text { fibers }\end{array}$ \\
\hline $\begin{array}{l}\text { NMuMG (normal } \\
\text { murine mammary } \\
\text { gland cell line) }\end{array}$ & TGF- $\beta ;$ T $\beta$ RI/Smads & $\begin{array}{c}\text { TFG- } \beta \text {; PI3K; } \\
\text { p38 MAPK; ERK/MAPK }\end{array}$ & $\begin{array}{c}\text { E-cadherin, Z0-1, } \\
\beta \text {-catenin downregulation }\end{array}$ & $\begin{array}{l}\text { Fibronectin } \\
\text { upregulation }\end{array}$ & $\begin{array}{l}\text { Actin stress } \\
\text { fibers }\end{array}$ \\
\hline $\begin{array}{l}\text { Mouse primary } \\
\text { hepatocytes }\end{array}$ & TGF- $\beta$ & TGF- $\beta$ & E-cadherin downregulation & $\begin{array}{l}\text { Vimentin, collagen } \\
\text { type I upregulation }\end{array}$ & $\begin{array}{l}\text { Actin stress } \\
\text { fibers }\end{array}$ \\
\hline $\begin{array}{l}\text { AML12 (normal } \\
\text { mouse hepatocyte } \\
\text { cell line) }\end{array}$ & TGF- $\beta$ & TGF- $\beta$; PKA; STAT3 & $\begin{array}{l}\text { E-cadherin, Z0-1 } \\
\text { downregulation }\end{array}$ & $\begin{array}{l}\text { Vimentin, collagen } \\
\text { type I upregulation }\end{array}$ & $\begin{array}{l}\text { Actin stress } \\
\text { fibers }\end{array}$ \\
\hline $\begin{array}{l}\text { MMH-D3 (immortalized } \\
\text { Met murine } \\
\text { hepatocytes) }\end{array}$ & $\begin{array}{c}\text { Cooperation of } \\
\text { Ha-RAS and TGF- } \beta\end{array}$ & $\begin{array}{c}\text { Autocrine TFG- } \beta \\
\text { and ERK/MAPK, PI3K }\end{array}$ & $\begin{array}{l}\text { E-cadherin, Z0-1, } \\
\text { desmoplakin, } \beta \text {-catenin } \\
\text { downregulation }\end{array}$ & $\begin{array}{l}\text { Fibronectin } \\
\text { upregulation }\end{array}$ & $\begin{array}{l}\text { Actin stress } \\
\text { fibers }\end{array}$ \\
\hline $\begin{array}{l}\text { SNU449 (human } \\
\text { primary hepatocellular } \\
\text { carcinoma cells) }\end{array}$ & TM4SF5 & $\begin{array}{l}\text { TM4SF5, integrins/FAK/ } \\
\text { RhoA (inactive) }\end{array}$ & $\begin{array}{c}\text { E-cadherin, Z0-1, } \\
\text { desmoplakin, } \beta \text {-catenin, } \\
\text { downregulation/delocalization }\end{array}$ & $\alpha$-SMA upregulation & $\begin{array}{l}\text { Aberrant actin } \\
\text { bundling }\end{array}$ \\
\hline
\end{tabular}

AData are from refs. 17-24. FAK, focal adhesion kinase; LEF, lymphoid enhancer binding factor; T $\beta R$ I, TGF- $\beta$ receptor I.

cells can dissociate from neighboring cells, invade adjacent tissue, and acquire the ability to move throughout the body and form metastases.

The interaction of various tetraspanins with integrins can regulate some of these processes. For example, tetraspanin family member CD151 has been found in complexes with $\beta_{1}$ integrins (11). This association increases the avidity of $\beta_{1}$ integrin binding to its ligand (12) and has also been shown to affect melanocyte motility in the skin (13). Expression of CD151 has also been shown to alter tumor metastasis, although the detailed mechanisms through which it mediates this effect are not yet clear (14). There is also evidence that tetraspanins modulate intracellular signaling (11).

EMT induced by tetraspanin TM4SF5 In their current study in this issue of the JCI, Lee et al. (15) build on their earlier study and unravel in part the molecular mechanisms by which TM4SF5 contributes to cancer progression. In a previous report, Lee et al. demonstrated that TM4SF5 is associated with the integrin $\alpha_{2}$ subunit and modulates actin organization and FAK signaling in Cos7 cells after serum stimulation (16), functions perhaps analogous to those of other tetraspanins. The authors have now taken their previous work further by showing that TM4SF5 overexpression in human hepatocarcinoma SNU449 cells brings about phenotypic changes in these cells that resemble EMT. This has pathological relevance because they also show that TM4SF5 is upregulated in human hepatocarcinoma tissues. The cells show elongated morphology, cell-cell contact loss, continuous growth, aberrant actin bundling, and a shift from epithelial cell marker to mesenchymal cell marker expression, i.e., downregulation of the tumor suppressor and epithelial cell adhesion molecule E-cadherin (independent of Snail1, a transcriptional repressor of E-cadherin), downregulation of the actin-binding protein zonula occludens-1 (ZO-1), and upregulation of $\alpha$-SMA (Figure 1, B and C). They suggest that TM4SF5 enhances the expression and cytosolic stabilization of the cyclin-dependent kinase inhibitor $\mathrm{p} 27^{\mathrm{Kip} 1}$, which in turn mediates RhoA inactivation. Subsequently, RhoA inactivation results in actin reorganization and cell elongation, leading to EMT. They propose that EMT may be responsible for the loss of cell-cell contact observed between TM4SF5-expressing SNU449 cells and that the loss of contact inhibition (the arrest of cell proliferation due to physical contact with other cells) results in uncontrolled cell growth and tumorigenesis. The authors go on to demonstrate that after subcutaneous injection of TM4SF5-expressing SNU449 cells into nude mice, these cells formed tumors capable of invading muscle and blood vessels. Together, the data demonstrate that overexpression of TM4SF5 induces classical cell transformation phenotypes and tumorigenicity (Figure 1).

There are both similarities and differences between the TM4SF5-induced EMT of SNU449 cells reported in this issue by Lee et al. (15) and the EMT models of mammary gland or hepatic origin (Table 1). In all EMT models, the expression of epithelial cell markers is downregulated, while that of mesenchymal cell markers is upregulated. In all such models, one of the distinct features of EMT is the formation of actin stress fibers (17-19), which are thought to contribute to increased cell motility. However, stress fiber formation was not observed by Lee et al. in their SNU449 cells in the current study. Also, in other EMT models (19-22), E-cadherin downregulation is mediated by the transcriptional repressor Snail1, but in the current study (15), TM4SF5induced EMT of SNU449 cells appeared to be independent of Snail1. Moreover, in NMuMG cells, RhoA was found to function as an upstream effector of Akt activation in response to TGF- $\beta$, the inducer of EMT in this cell system (23), which is in contrast to the effect of Akt as the upstream effector to inhibit RhoA as reported here (15). The current study by Lee et al. therefore highlights a previously unidentified mechanism for inducing EMT with relevance for hepatocellular carcinoma. Furthermore, it describes 
a variant EMT phenotype induced by the tumor-specific antigen TM4SF5.

Address correspondence to: Ruth J. Muschel, Radiation Oncology and Biology, The Radiobiology Research Institute, Churchill Hospital, University of Oxford, Oxford OX3 7LJ, United Kingdom. Phone: 44-01865-857-427; Fax: 44-0-1865-857-533; E-mail: ruth.muschel@rob.ox.ac.uk.

1. Gress, T.M., et al. 1997. Identification of genes with specific expression in pancreatic cancer by cDNA representational difference analysis. Genes Chromosomes Cancer. 19:97-103.

2. Muller-Pillasch, F., et al. 1998. Identification of a new tumour-associated antigen TM4SF5 and its expression in human cancer. Gene. 208:25-30.

3. Wright, M.D., Ni, J., and Rudy, G.B. 2000. The L6 membrane proteins - a new four-transmembrane superfamily. Protein Sci. 9:1594-1600.

4. Chang, Y.W., et al. 2005. CD13 (aminopeptidase N) can associate with tumor-associated antigen L6 and enhance the motility of human lung cancer cells. Int. J. Cancer. 116:243-252.

5. Lazo, P. 2007. Functional implications of tetraspanin proteins in cancer biology. Cancer Sci. 98:1666-1677.

6. Hay, E.D. 1995. An overview of epithelio-mesenchymal transformations. Acta Anat. 154:8-20.

7. Kiemer, A.K., Takeuchi, K., and Quinlan, M.P. 2001. Identification of genes involved in epithelialmesenchymal transition and tumor progression.
Oncogene. 20:6679-6688

8. Janda, E., et al. 2002. Ras and TGF[beta] cooperatively regulate epithelial cell plasticity and metastasis: dissection of Ras signaling pathways. J. Cell Biol. 156:299-313

9. Vincent-Salomon, A., and Thiery, J.P. 2003. Host microenvironment in breast cancer development: epithelial-mesenchymal transition in breast cancer development. Breast Cancer Res. 5:101-106.

10. Xue, C., Plieth, D., Venkov, C., Xu, C., and Neilson, E.G. 2003. The gatekeeper effect of epithelialmesenchymal transition regulates the frequency of breast cancer metastases. Cancer Res. 63:3386-3394.

11. Hemler, M.E. 2005. Tetraspanin functions and associated microdomains. Nat. Rev. Mol. Cell Biol. 6:801-811.

12. Lammerding, J., Kazarov, A.R., Huang, H., Lee, R.T., and Hemler, M.E. 2003. Tetraspanin CD151 regulates alpha6beta1 integrin adhesion strengthening. Proc. Natl. Acad. Sci. U. S. A. 100:7616-7621.

13. Garcia-Lopez, M.A., et al. 2005. Role of tetraspanins CD9 and CD151 in primary melanocyte motility. J. Invest. Dermatol. 125:1001-1009.

14. Testa, J.E., Brooks, P.C., Lin, J.M., and Quigley, J.P. 1999. Eukaryotic expression cloning with an antimetastatic monoclonal antibody identifies a tetraspanin (PETA-3/CD151) as an effector of human tumor cell migration and metastasis. Cancer Res. 59:3812-3820.

15. Lee, S.-A., et al. 2008. Tetraspanin TM4SF5 mediates loss of contact inhibition through epithelialmesenchymal transition in human hepatocarcinoma. J. Clin. Invest. 118:1354-1366.

16. Lee, S.Y., et al. 2006. Focal adhesion and actin organization by a cross-talk of TM4SF5 with integrin alpha2 are regulated by serum treatment. Exp. Cell Res. 312:2983-2999.
17. Gal, A., et al. 2008. Sustained TGFbeta exposure suppresses Smad and non-Smad signalling in mammary epithelial cells, leading to EMT and inhibition of growth arrest and apoptosis. Oncogene. 27:1218-1230.

18. Gotzmann, J., et al. 2004. Molecular aspects of epithelial cell plasticity: implications for local tumor invasion and metastasis. Mutat. Res. 566:9-20.

19. Kaimori, A., et al. 2007. Transforming growth factor-beta 1 induces an epithelial-to-mesenchymal transition state in mouse hepatocytes in vitro. J. Biol. Chem. 282:22089-22101.

20. Gotzmann, J., et al. 2002. Hepatocytes convert to a fibroblastoid phenotype through the cooperation of TGF-beta1 and Ha-Ras: steps towards invasiveness. J. Cell Sci. 115:1189-1202.

21. Huber, M.A., Kraut, N., and Beug, H. 2005. Molecular requirements for epithelial-mesenchymal transition during tumor progression. Curr. Opin. Cell Biol. 17:548-558.

22. Moustakas, A., and Heldin, C.H. 2007. Signaling networks guiding epithelial-mesenchymal transitions during embryogenesis and cancer progression. Cancer Sci. 98:1512-1520.

23. Bakin, A.V., Tomlinson, A.K., Bhowmick, N.A., Moses, H.L., and Arteaga, C.L. 2000. Phosphatidylinositol 3-kinase function is required for transforming growth factor beta-mediated epithelial to mesenchymal transition and cell migration. J. Biol. Chem. 275:36803-36810.

24.Yang, Y., et al. 2006. Regulation of transforming growth factor- $\beta 1$-induced apoptosis and epithelial-to-mesenchymal transition by protein kinase A and signal transducers and activators of transcription 3. Cancer Res. 66:8617-8624.

\title{
HOXB4 and retroviral vectors: adding fuel to the fire
}

\author{
Andre Larochelle and Cynthia E. Dunbar
}

Molecular Hematopoiesis Section, Hematology Branch, National Heart, Lung, and Blood Institute, National Institutes of Health, Bethesda, Maryland, USA.

\begin{abstract}
The transcription factor homeobox B4 (HOXB4) is a promising agent capable of providing a growth advantage to genetically modified hematopoietic stem and progenitor cells (HSPCs). In this issue of the JCI, Zhang and colleagues overexpressed HOXB4 in HSPCs from large animals using retroviral vectors (see the related article beginning on page 1502). Two years after transplantation, most animals developed leukemia, a consequence of combined HOXB4 and deregulated protooncogene expression. These results highlight the risks of combining integrating vectors and growth-promoting genes for clinical applications.
\end{abstract}

\section{Hematopoietic stem cells and gene therapy}

Hematopoietic stem and progenitor cells (HSPCs) are ideal targets for permanent

Nonstandard abbreviations used: HOXB4, homeobox B4; HSPC, hematopoietic stem and progenitor cell; IL2RG, IL-2 receptor $\gamma$; LMO2, LIM domain only 2; SCID-X, X-linked SCID.

Conflict of interest: The authors have declared that no conflict of interest exists.

Citation for this article: J. Clin. Invest. 118:1350-1353 (2008). doi:10.1172/JCI35326. genetic correction of defects in any lineage of hematopoietic cells. Most clinical applications have used gene transfer vectors based on integrating retroviruses, but the relative inefficiency of these vectors has limited the considerable potential of gene transfer into HSPCs. Genetically modified cells represent only a small fraction $(1 \%-10 \%)$ of the hematopoietic cells after transplantation. Consequently, competition from unmodified infused and endogenous HSPCs may dilute any therapeutic effect of the transduced cells. This implies that this small fraction of genetically modified hematopoietic cells will correct diseases requiring more than $1 \%-10 \%$ of corrected cells only if they have a marked selective growth advantage in vivo.

\section{Homeobox B4 promotes a selective growth advantage of transduced HSPCs}

In most diseases considered to be suitable targets for gene therapy, corrected cells do not themselves have an inherent growth advantage, providing an impetus to arm retroviral vectors with genes capable of conferring a selective growth advantage to transduced HSPCs and their progeny in vivo. Ectopic expression of homeobox B4 (HOXB4), a transcription factor containing a highly conserved DNA-binding motif known as the homeodomain, has been found to enhance HSPC self-renewal in vitro and in vivo and has been suggested as an 